\title{
EXCREÇÃO URINÁRIA DE URÉIA, ÁCIDO ÚRICO E AMÔNIA EM PINGÜINS PYGOSCELLIDAE E. RODRIGUES ${ }^{1}$; C.S. CARVALHO ${ }^{2}$; L.M. SALVO ${ }^{2}$; M. BACILA ${ }^{2}$
}

Estação Antártica Comandante Ferraz, Ilha do Rei George - Antártica. ${ }^{1}$ Faculdade de Ciências Farmacêuticas - USF.

${ }^{2}$ Laboratório de Piscicultura - Setor de Ciências Agrárias - Universidade Federal do Paraná.

Estudando o metabolismo nitrogenado de aves antárticas RODRIGUES et al. (Antarctic Record. 42(1):111119, 1998), constataram níveis elevados de uréia no sangue e de arginase em fígado e rins de pingüins, semelhantes aos níveis encontrados em mamíferos. O presente trabalho objetivou verificar as concentrações de ácido úrico, ureia e amônia na urina de pingüins Pygoscellidae da Região Antártica. Os exemplares de pingüins capturados próximo à Estação Antártica Comandante Ferraz - Ilha Rei George - Antártica, foram imobilizados e as amostras de urina colhidas na saída do ureter, como reflexo da situação de stress. Somente amostras urinárias claras, sem contaminação com fezes, foram utilizadas para dosagens de ácido úrico, uréia e amônia. Amostras de urina de Pygoscellis antarctica $(\mathrm{n}=2)$, P. Adeliae $(\mathrm{n}=16)$ e P. Papua $(\mathrm{n}=11)$ foram diluídas com solução gelada de carbonato de sódio $0,2 \%(\mathrm{p} / \mathrm{v})$ e agitadas em banho de gelo até que todo o precipitado branco fosse dissolvido. A concentração de uréia foi determinada segundo o método da urease como descrito por BERGMEYER (Methods of Enzymatic Analysis. 3ed., Vol. 9. Florida VCH Publ. 449-453, 1985), o ácido úrico analisado pelo método da uricase como descrito por BARHAN e TRINDER (P. Analyst. 97:142, 1972) e amônia determinada pelo método colorimétrico do nitroprussiato. As concentrações de ácido úrico, uréia e amônia na urina de pingüins Pygoscellidae em estado nativo estão apresentadas na tabela 1 . O perfil excretório dos compostos nitrogenados presentes na urina comparado aos níveis dos mesmos no sangue de $P$. antarctica, $P$. adeliae e $P$. papua, deixa clara a capacidade ureogênica e o metabolismo excretório uricotélico característico das aves.

Tabela 1. Níveis de uréia, ácido úrico e amônia na urina de pinguis Pygoscellidae em estado nativo.

\begin{tabular}{l|l|l|l}
\hline Pingüin & Uréia $(\mathrm{mMol} / \mathrm{L})$ & Ác. Úrico $(\mathrm{mMol} / \mathrm{L})$ & Amônia $(\mathrm{mMol} / \mathrm{L})$ \\
\hline Pygocellis papua & $165,7 \pm 39,7$ & $959,4 \pm 210,2$ & $350,4 \pm 56,3$ \\
P. adeliae & $110,5 \pm 37,5$ & $984,7 \pm 338,3$ & $206,6 \pm 121,6$ \\
P. antarctico & $351,8 \pm 91,3$ & $597,6 \pm 73,8$ & $383,8 \pm 123,7$ \\
\hline Apoio:
\end{tabular}

Apoio: CNPq-PROANTAR 